\title{
Simulation of hurricane response to suppression of warm rain by sub-micron aerosols
}

\author{
D. Rosenfeld ${ }^{1}$, A. Khain ${ }^{1}$, B. Lynn ${ }^{1}$, and W. L. Woodley ${ }^{2}$ \\ ${ }^{1}$ Institute of Earth Sciences, The Hebrew University of Jerusalem, Israel \\ ${ }^{2}$ Woodley Weather Consultants, 11 White Fir Court, Littleton 80127, USA \\ Received: 5 April 2007 - Published in Atmos. Chem. Phys. Discuss.: 26 April 2007 \\ Revised: 22 June 2007 - Accepted: 25 June 2007 - Published: 2 July 2007
}

\begin{abstract}
The feasibility of hurricane modification was investigated for hurricane Katrina using the Weather Research and Forecasting Model (WRF). The possible impact of seeding of clouds with submicron cloud condensation nuclei $(\mathrm{CCN})$ on hurricane structure and intensity as measured by nearly halving of the area covered by hurricane force winds was simulated by "turning-off" warm rain formation in the clouds at Katrina's periphery (where wind speeds were less than $22 \mathrm{~m} \mathrm{~s}^{-1}$ ). This simplification of the simulation of aerosol effects is aimed at evaluating the largest possible response. This resulted in the weakening of the hurricane surface winds compared to the "non-seeded" simulated storm during the first $24 \mathrm{~h}$ within the entire tropical cyclone (TC) area compared to a control simulation without warm rain suppression. Later, the seeding-induced evaporative cooling at the TC periphery led to a shrinking of the eye and hence to some increase in the wind within the small central area of the TC. Yet, the overall strength of the hurricane, as defined by the area covered by hurricane force winds, decreased in response to the suppressed warm rain at the periphery, as measured by a $25 \%$ reduction in the radius of hurricane force winds. In a simulation with warm rain suppression throughout the hurricane, the radius of the hurricane force winds was reduced by more than $42 \%$, and although the diameter of the eye shrunk even further the maximum winds weakened. This shows that the main mechanism by which suppressing warm rain weakens the TC is the low level evaporative cooling of the un-precipitated cloud drops and the added cooling due to melting of precipitation that falls from above.
\end{abstract}

Correspondence to: D. Rosenfeld

(daniel.rosenfeld@huji.ac.il)

\section{Introduction}

The devastating United States hurricane season of 2005 renewed interest in developing methods to mitigate the strong winds of hurricanes. Hurricane modification can be considered if it is possible to intervene in the energy pathways in moist tropical convective clouds that energize hurricanes. These energy pathways (see illustration in Fig. 1) start with heat that is taken from the sea surface mainly by evaporation (Fig. 1A). This latent heat becomes sensible when the vapor condenses into cloud drops (Fig. 1B). Some of this released heat is reclaimed if the drops re-evaporate (Fig. 1C), but the heat remains in the air if the drops precipitate as rain (Fig. 1D). Drops that ascend to the sub-zero parts of the cloud freeze and release additional latent heat of freezing (Fig. 1E), which along with the freezing of the ascending vapor warm the upper levels of the cloud (Fig. 1G). Some of the heat is lost when ice evaporates aloft (Fig. 1I). The rest of the heat remains in the cloud when the ice hydrometeors precipitate and melt while cooling the air below (Fig. 1H). This study tests the feasibility of modifying hurricanes by seeding with small CCN to suppress warm rain (Fig. 1D). This would increase the warming aloft (Figs. 1E and G) and the evaporative cooling at the lower levels (Figs. $1 \mathrm{C}$ and $\mathrm{H}$ ) and so affect the storm circulation in ways that will be shown herein.

Historically the pathway of freezing supercooled cloud water (Fig. 1E) was addressed by glaciogenic cloud seeding. Hurricane mitigation was first attempted between 1962 and 1983 in the framework of project STORMFURY by the US government (Willoughby et al., 1985). The envisioned modification technique involved artificial stimulation of convection at the outer periphery of the eyewall through seeding of strong convective cloud towers with silver iodide for the purpose of freezing super-cooled water (water in liquid state but colder than $0^{\circ} \mathrm{C}$ ). They postulated that the release of the latent heat of freezing (pathway E in Fig. 1) would invigorate convection (Simpson and Malkus, 1964) that would

Published by Copernicus Publications on behalf of the European Geosciences Union. 


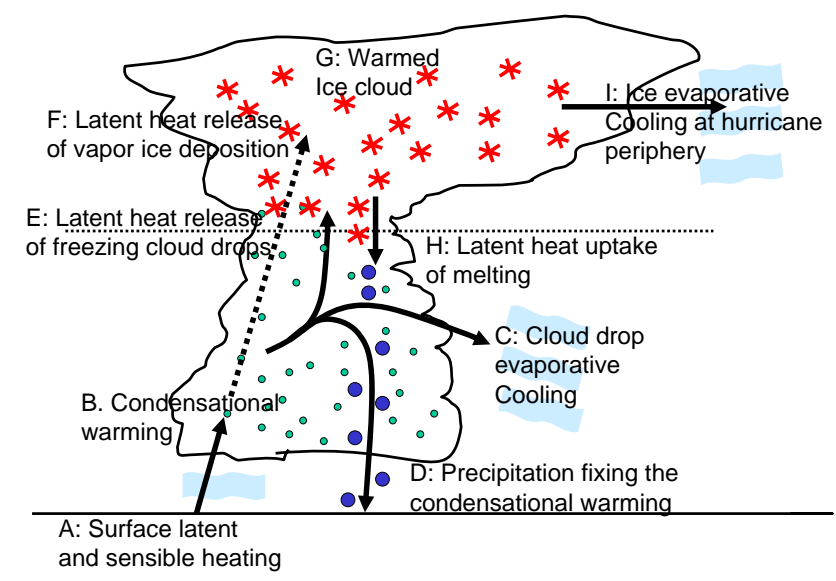

Fig. 1. Energy pathways in the convective clouds that energize hurricanes. The heat that is taken from the sea surface mainly by evaporation (A) is released when the vapor condenses into cloud drops (B). Some of this released heat is reclaimed if the drops re-evaporate (C) and return to vapor. The heat remains in the air if the drops precipitate as rain (D). Drops that ascend to the sub-zero parts of the cloud freeze there and release additional latent heat of freezing $(\mathrm{E})$, which along with the freezing of ascending vapor warm the upper levels of the cloud (G). Some of the heat is lost when ice evaporates aloft (I). The rest of the heat remains in the cloud when the ice hydrometeors precipitate and melt while cooling the air below $(\mathrm{H})$. Seeding by small CCN to suppress warm rain (D) would increase the warming aloft (E and $\mathrm{G}$ ) and evaporative cooling at the lower levels $(\mathrm{C}$ and $\mathrm{H})$.

compete with the original eyewall, leading to its reformation at a larger radius, and thus, through partial conservation of angular momentum, produce a decrease in the strongest winds. Since a hurricane's destructive potential increases with the cube of its strongest winds, a reduction as small as $10 \%$ in its wind speed could significantly reduce the destructive power of hurricanes, which is proportional to the cube of the wind speed.

Modification was attempted in four hurricanes. Although the maximum winds of some of the seeded TCs decreased, the change in hurricane intensity was attributed to natural intensity fluctuations rather than to seeding. The analysis of the microphysical structure of tropical convective (TC) clouds (Willoughby et al., 1985) showed that at the levels where seeding was applied there was too little supercooled water and a significant amount of cloud ice. Consequently, the glaciogenic seeding was not likely to affect cloud dynamics, at least in the way assumed in the STORMFURY conceptual model. Today it is known that the quick conversion of cloud water into raindrops (Pathway B in Fig. 1) in maritime tropical convection causes the clouds to lose much of their water by rain out and evaporation (Pathway $\mathrm{C}$ ) before ascending above the $0^{\circ} \mathrm{C}$ isotherm.

This study was motivated initially by earlier observations that a heavy load of small aerosols can prevent warm rain from tropical clouds (Rosenfeld, 1999; Rosenfeld and Woodley, 2003; Andreae et al., 2004), and hence allow the cloud water to ascend to the supercooled levels and become available for freezing, and so remedy the cardinal problem of STORMFURY, which is insufficient amounts of supercooled water. The low amounts of supercooled water are caused by the very efficient warm rain processes and early rainout in tropical maritime convective clouds (Jorgensen and LeMone, 1989; Stith et al., 2002). The remaining large supercooled cloud and rain drops freeze readily a short distance (less than $1 \mathrm{~km}$ ) above the $0^{\circ} \mathrm{C}$ isotherm level (Black and Hallett, 1986). The new approach to weaken hurricanes by seeding with submicron hygroscopic aerosols was submitted on April 2006 as a proposal to the Yeshaya Horowitz Association, and filed as a provisional patent in early 2007. This alternative approach was developed further in this study based on the observations mentioned above as well as on the results of numerical simulations (Khain et al., 2005; Lynn et al., 2005, Van den Heever et al., 2006) indicating that an increase in the concentration of small aerosol particles (AP) leads to the formation of a great number of small droplets with low collision rates. The delay in the raindrop formation and rainout from the lower parts of the clouds leads to a greater amount of water advected to above the $0^{\circ} \mathrm{C}$ isotherm, where freezing occurs mostly below $-10^{\circ} \mathrm{C}$ (Rosenfeld, 1999 and 2000; Rosenfeld and Woodley, 2003; Andreae et al., 2004). This results in at least partial suppression of raindrop formation in the lower parts of the clouds and to additional latent heat release at high levels because of drop freezing and extra water vapour condensation on droplets and ice particles. Consequently, clouds developing in a polluted atmosphere turn out to be more intense and reach higher levels than clouds developing in a less polluted air mass. The melting of the ice hydrometeors at lower levels causes enhanced cooling and downdrafts that can trigger new convective elements. This convective invigoration effect was proposed in Williams et al. (2002), described by Rosenfeld (2006 and 2007), observed by Koren et al. (2005), Myhre et al. (2007) and Lin et al. (2006), and simulated by Khain et al. (2004 and 2005), Lynn et al. (2005) and Van den Heever et al. (2006).

These observational and numerical results indicate a possibility of mitigating tropical cyclones (TC) by seeding the air that is ingested into the cloud bases with large concentrations $\left(1000-2000 \mathrm{~cm}^{-3}\right)$ of small ( 0.1 to $0.2 \mu \mathrm{m}$ diameter) cloud condensation nuclei $(\mathrm{CCN})$. It was proposed that the expected convective invigoration at the hurricane periphery should decrease the influx of air mass to the hurricane center and decrease, therefore, the ascending vapour mass and the latent heat release in the eyewall. That is, seeding of small $\mathrm{CCN}$ to suppress warm rain (Fig. 1D) in hurricanes could lead to a relative weakening of the storm, at least initially. This is because the seeding should increase the warming aloft (Figs. 1E and G) and evaporative cooling at the lower levels (Figs. $1 \mathrm{C}$ and $\mathrm{H}$ ).

This conceptual model was tested using a two nested grid 


\section{Control}

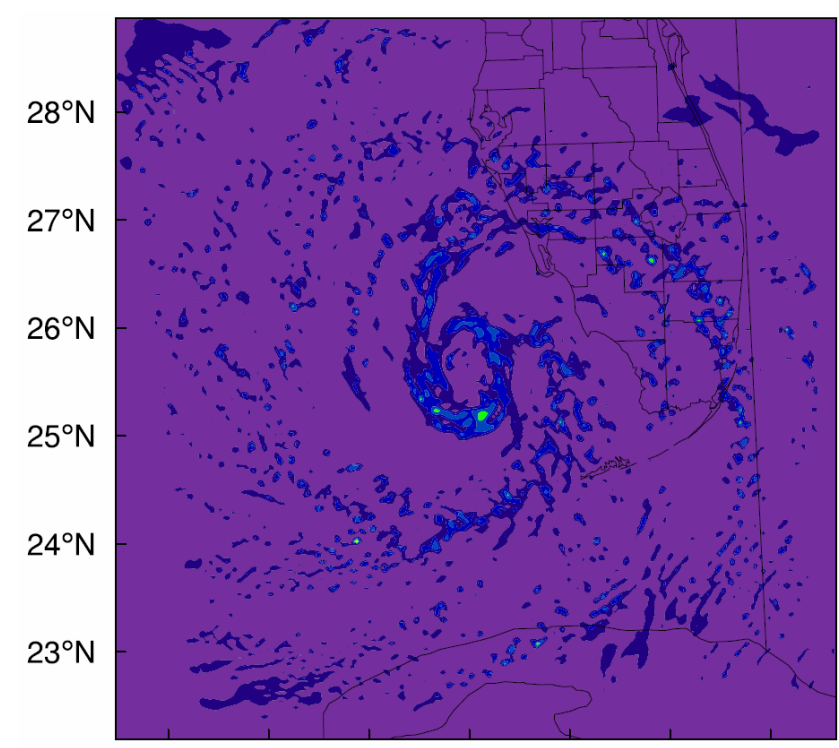

$86^{\circ} \mathrm{W} 85^{\circ} \mathrm{W} 84^{\circ} \mathrm{W} 83^{\circ} \mathrm{W} 82^{\circ} \mathrm{W} 81^{\circ} \mathrm{W} 80^{\circ} \mathrm{W}$
Seeded NWRP

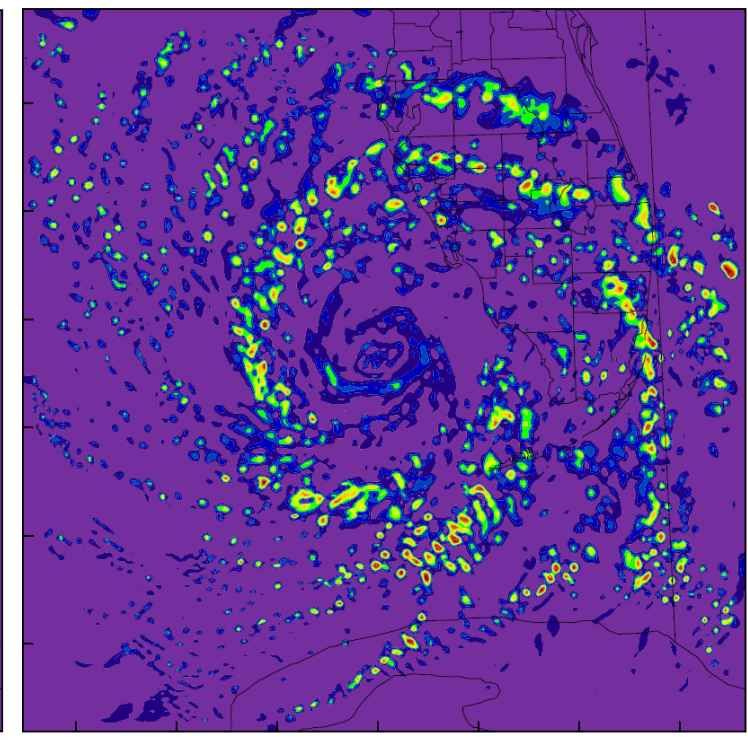

$86^{\circ} \mathrm{W} 85^{\circ} \mathrm{W} 84^{\circ} \mathrm{W} 83^{\circ} \mathrm{W} 82^{\circ} \mathrm{W} 81^{\circ} \mathrm{W} 80^{\circ} \mathrm{W}$

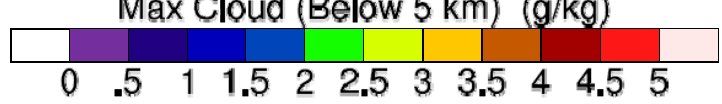

Fig. 2. Maximum cloud water contents in clouds of "natural" and "seeded" hurricane runs at 27 July 2005 18:00 UT. "Seeding" leads to a significant increase in mass of cloud water reaching supercooled levels, especially at the storm periphery.
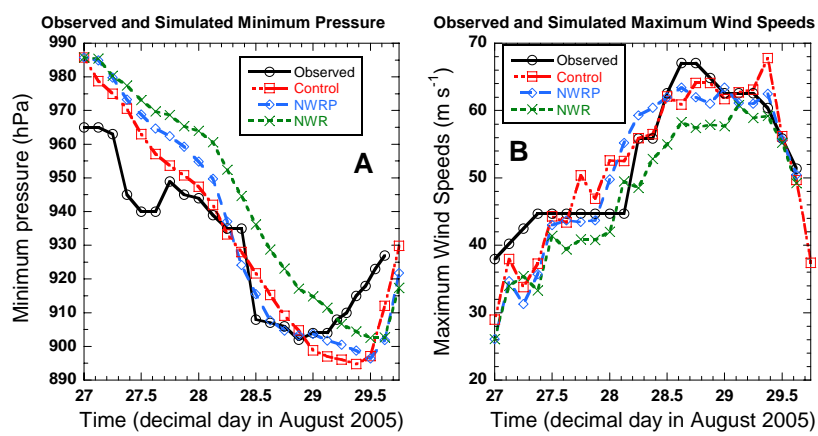

Fig. 3. Time dependence of minimum surface pressure (A) and maximum wind speed (B) in three simulations: Control warm rain (WR) marked red, NWR (no warm rain allowed) marked green and NWRP (no warm rain allowed at the TC periphery) marked blue. The observed values of Katrina are shown by the thin black line. The deviation of pressure in the numerical simulations from that in real Katrina can be attributed by inexact assimilation of initial data in the model.

Weather Research Model (WRF: Michalakes et al. (2005), Skamarock et al. (2005), Michalakes et al. (2001)) by simulating the evolution of hurricane Katrina during 27-29 August 2005. Given this focus of the exploratory study, the simulations are purposely crude, where warm rain processes are set completely on or off at the periphery, in order to reveal the greatest possible aerosol effects on hurricane peak intensity (minimum pressure, and maximum winds) and overall strength (radius of area covered by hurricane force winds and wind speed outside of the radius of maximum wind). The paper also discusses some new physical insights that result from an analysis of the three-dimensional temperature, humidity, and cloud fields.

Cotton et al. (2007) also simulated the possible impacts of CCN seeding of hurricanes. They simulated the evolution of an idealized TC starting with a weak initial vortex using the Regional Atmospheric Modeling System (RAMS) model (Cotton et al., 2003) with a two moment microphysical scheme (Saleeby and Cotton, 2004). The TC was simulated at $2 \mathrm{~km}$ horizontal resolution. The seeding effect was simulated by adding 1000 or $2000 \mathrm{CCN} \mathrm{cm}{ }^{-3}$, compared to the natural background of $100 \mathrm{~cm}^{-3}$. The TC developing in dusty air was substantially weaker at the mature stage compared to the storm developing in the clean air, with peak winds lower by $25 \mathrm{~ms}^{-1}$ and central pressure higher by $25 \mathrm{hPa}$. Adding giant $\mathrm{CCN}$ that restored the warm rain, however, eliminated most of the TC weakening. 

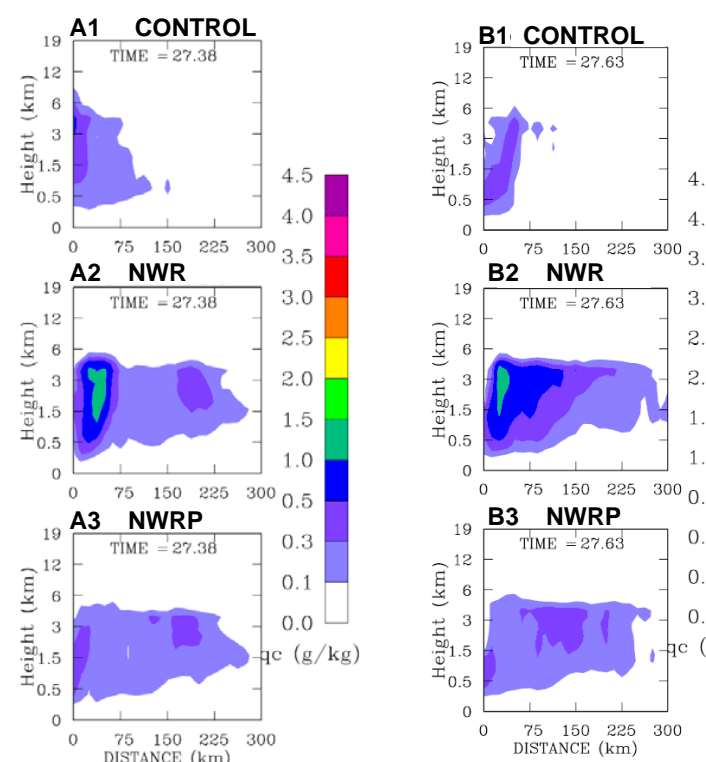

4.5
4.0
3.5

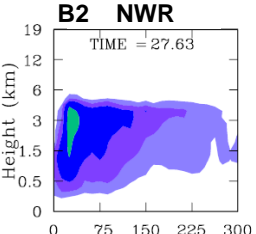

3.0
2.5
2.0
1.5
1.0
0.5
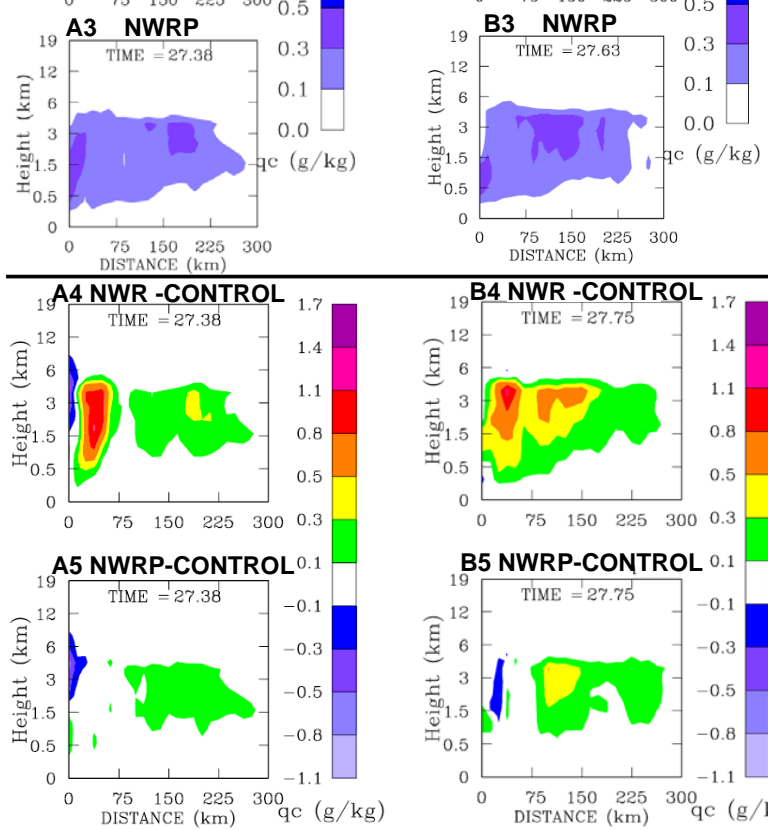
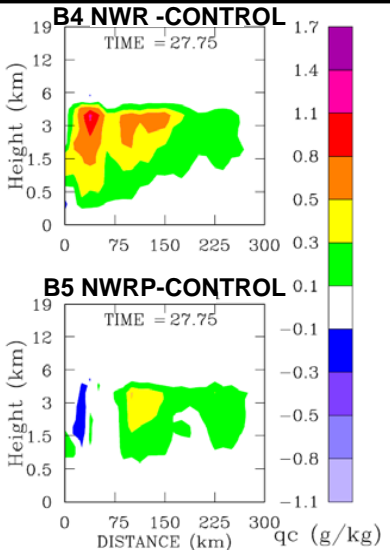

C1 CONTROL

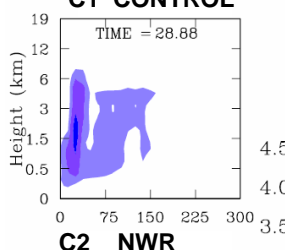

${ }_{19}$ C2 NWR

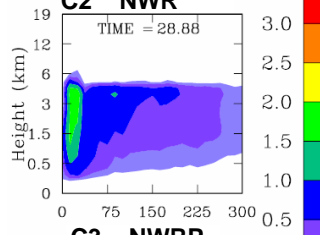

C3 NWRP

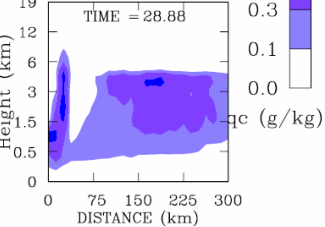

${ }_{19}$ C4 NWR -CONTROL

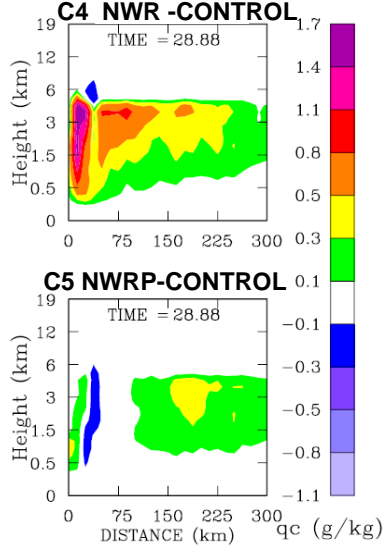

Fig. 4. (a) Vertical-radial cross sections of the azimuthally averaged cloud water content (CWC) in three simulations at different time instances (upper panels) and the differences of CWC between the NWR and NWRP on one hand and control (WR) simulations. The panels are marked by letters (A, B, C) denoting different time instances and by the times in decimals of day.

\section{Design of the numerical experiments}

A two nested grid of the Weather Research and Forecasting Model (NCAR WRF ARW version) was used to simulate Hurricane Katrina from 27 August 0z to 30 August 0z. The available computer resources (a 16 processor Linux cluster) were enough to simulate resolutions for the finest and the outer grid of $3 \mathrm{~km}$ and $9 \mathrm{~km}$, respectively. The bulkparameterization by Thompson et al. (2004) was used in the cloud-resolving simulations on both grids, while the coarse grid used both the bulk microphysics and the Kain-Fritsch cumulus convective scheme (Kain and Fritsch, 1993).

The WRF initial conditions were obtained from the Global Forecast System (GFS) Reanalysis data with a grid resolution of $30 \mathrm{~km}$. The analyzed reanalysis fields were used "as-is" to create the initial hurricane vortex. The vortex developed within several minutes of simulation time into a hurricane.
The atmospheric lateral boundary conditions of simulation were updated every three hours using GFS Reanalysis data. The sea surface temperatures were obtained from the Global Forecast System analysis data file for 00:00 UT 27 August.

The natural or control run, aimed at simulating the actual conditions in Katrina, allowed for warm rain (WR) formation by drop-drop collisions. The effect of sub-micron hygroscopic aerosols on warm rain processes was simulated in two other runs. Since small aerosols lead to the formation of a great number of small droplets with very low ability to form raindrops, the aerosol effects in the "seeding" runs were parameterized by shutting off the drop-drop collisions. In the first experimental simulation named "No Warm Rain" (NWR), the warm rain formation was shut off over the entire TC area. The NWR represents the "reference" simulation carried out under idealized conditions, which cannot occur in real hurricanes, because wind driven sea spray particles serve 

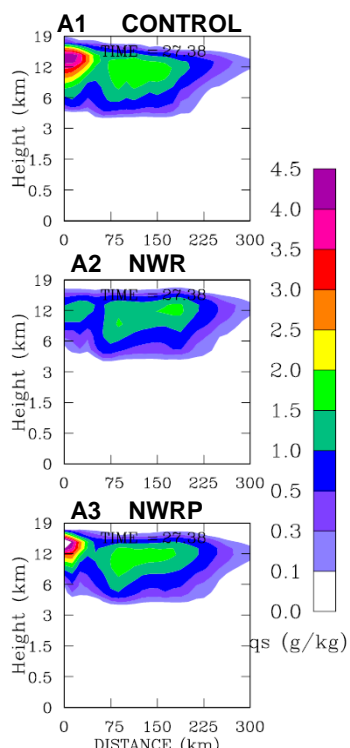

DISTANCE $(\mathrm{km})$

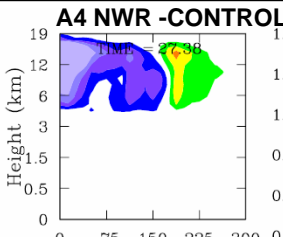

$\begin{array}{llllll}0 & 75 & 150 & 225 & 300 & 0.3\end{array}$
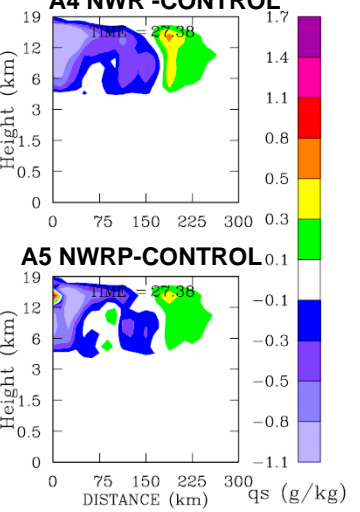

B1 CONTROL

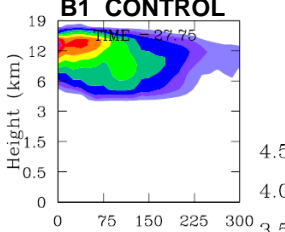

B2 NWR

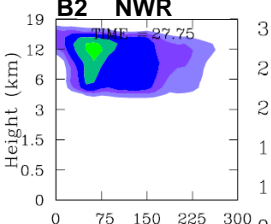

B3 NWRP

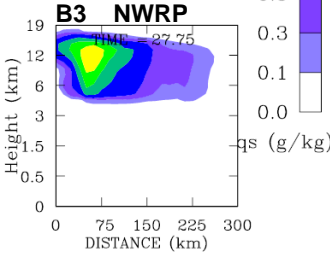

DISTANCE $(\mathrm{km})$

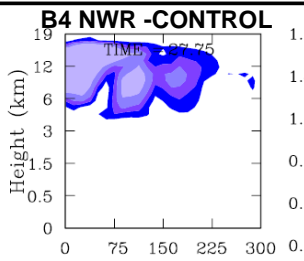

B5 NWRP-CONTROL
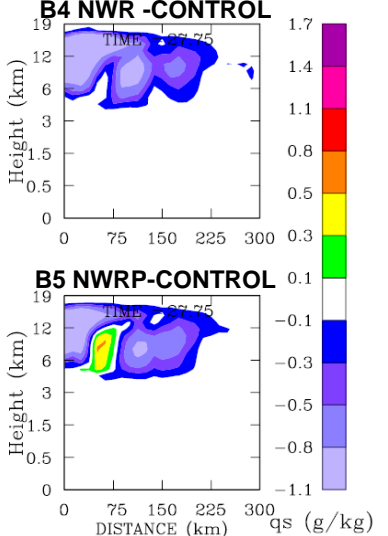

C1 CONTROL

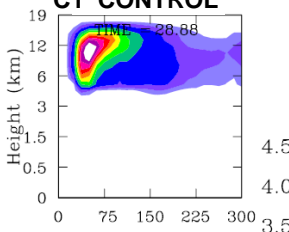

C2 NWR

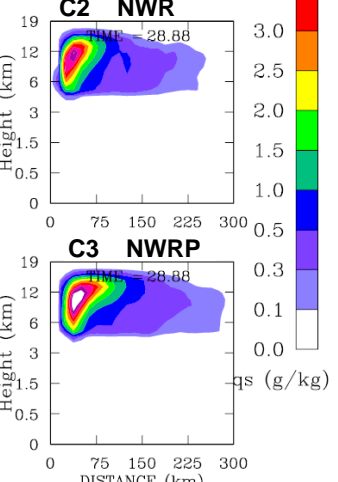

$\begin{array}{cccc}75 & 150 & 225 & 30 \\ 0 & 30\end{array}$

${ }_{19}$ C4 NWR -CONTROL

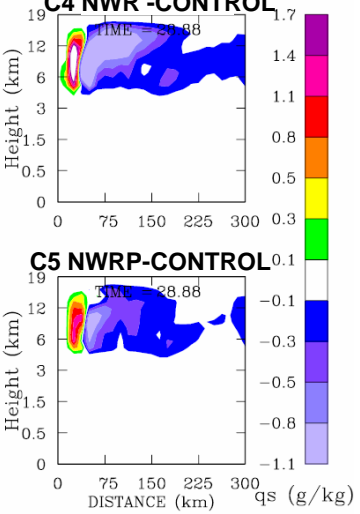

Fig. 4. (b) The same as in Fig. 4a, but for ice content.

as giant $\mathrm{CCN}$ ( $>1 \mu \mathrm{m}$ diameter) that initiate early rain even when large concentrations of small CCN exist (Woodcock, 1953, Segal et al., 2004). Woodcock (1953) measured, just below cloud base of clouds of a tropical cyclone near Florida, $10 \mu \mathrm{m}$ diameter wet sea spray particles at a concentration of $1 \mathrm{~cm}^{-3}$ under hurricane force winds $\left(32 \mathrm{~ms}^{-1}\right)$. The concentration of $22 \mu \mathrm{m}$ sea spray particles was $0.3 \mathrm{~cm}^{-3}$, and $47 \mu \mathrm{m}$ particles at $0.1 \mathrm{~cm}^{-3}$. Such concentration of ultragiant $\mathrm{CCN}$ should overwhelm the rain suppression seeding effect even in clouds with very small drops.

The second experimental simulation, referred to as No Warm Rain at the Periphery (NWRP), tests the impact of seeding aerosols only on the hurricane periphery, where the surface wind was smaller than $22 \mathrm{~m} \mathrm{~s}^{-1}$. This threshold is near the lower bound of Beaufort 9 wind, which is defined at sea by "spray may affect visibility." The presence of high concentrations of sea spray would most likely render ineffective any seeding of clouds with large concentrations of small $\mathrm{CCN}$. Hence, warm rain is turned off only in that part of the hurricane that has winds speeds less than the threshold value.

Figure 2 illustrates the effect of turning off warm rain processes on cloud liquid water content in the NWRP run compared to the Control (WR) run. One can see a dramatic increase in the LWC in clouds at the periphery of the seeded hurricane, in response to turning off the warm rain collision processes. Such an increase is consistent with past work using more sophisticated models (Khain et al., 2004, 2005; Lynn et al., 2005a, b; among others). In situ, this can be explained by the slower transformation of cloud droplets to raindrops in polluted clouds that occurs because polluted clouds create many small droplets which are too small to collide and coalesce efficiently.

\section{Results}

The simulated data were saved every three hours. The track of the simulated storms each curved to the north at an earlier time than the observed Katrina, and each made landfall about 

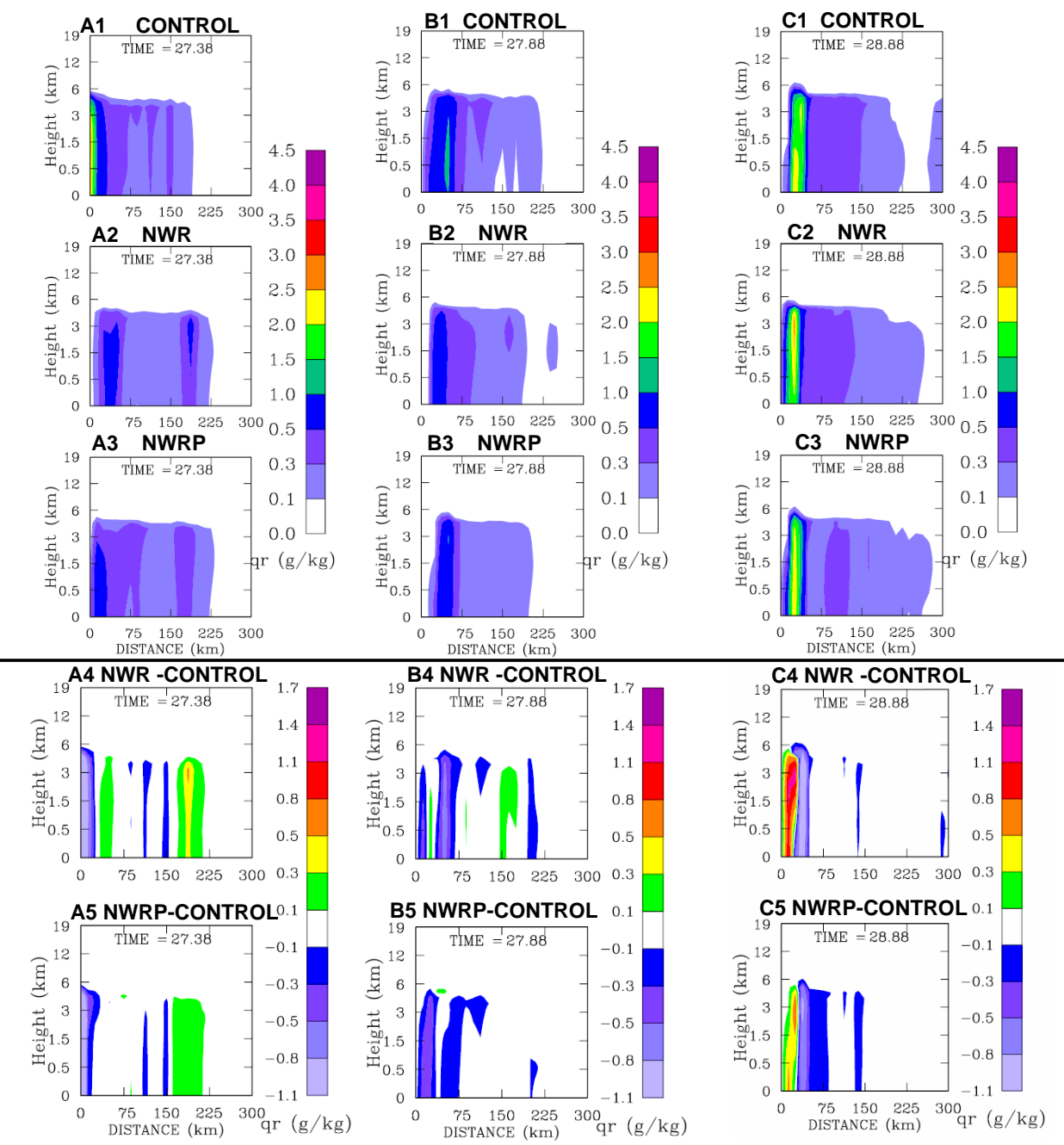

Fig. 4. (c) The same as in Fig. 4a, but for rain water content.

$200 \mathrm{~km}$ to the east of actual landfall of the observed storm (not shown). Nevertheless, the model was able to reproduce the main features of the hurricanes evolution, including the formation of the super hurricane with the minimum pressure of about $900 \mathrm{hPa}$ (Fig. 3). For instance, Figs. 3a and 3b show the simulated surface minimum pressure and maximum wind speeds, which are compared to the three hourly observational data from the National Hurricane Center. Within three hours of simulation time, the modelled Katrinas had reached hurricane intensity with maximum wind speed greater than $32.5 \mathrm{~m} \mathrm{~s}^{-1}$ and with minimum surface pressure of at least $965 \mathrm{hPa}$ (Fig. 3a), The simulated maximum winds then approach the observed values and then quite closely agree with observations after about $15 \mathrm{~h}$ of simulation time (Fig. $3 \mathrm{~b}$ ). Within the first $24 \mathrm{~h}$, the simulated minimum pressures were less than the control run in both NWR and NWRP. However, after this time the simulated minimum surface pressures in NWRP are less than in the Control run, with a concurrent increase in maximum wind speed. In contrast, the simulated minimum pressures and maximum wind speeds in NWR remain higher and less than the control values.

Figure 4 shows vertical cross sections of azimuthally averaged fields of cloud water content (CWC), rain water content (RWC), cloud ice, temperature, pressure, relative humidity, radial and tangential wind components, which are presented for each of the simulations at the times $t=27: 09,27: 18$ and 28:21 (day in August 2005: hour UT). In each simulation, the model reproduced the typical structure of a TC with an eye wall with strongly precipitating clouds, a warm core with negative vertical velocity in the TC eye, and the inflow layer in the lower and outflow layer in the upper troposphere. The radius of maximum winds varies between 30 and $50 \mathrm{~km}$ from the center. According to Fig. 4a the cloud water content increased in the NWRP compared to Control, and further increased in the NWR simulation. By $24 \mathrm{~h}(\mathrm{t}=28: 00)$ the changes in the TC structure caused by warm rain prevention are remarkable. The main changes in microphysical structure are: the increase in CWC within the radial range annulus of 

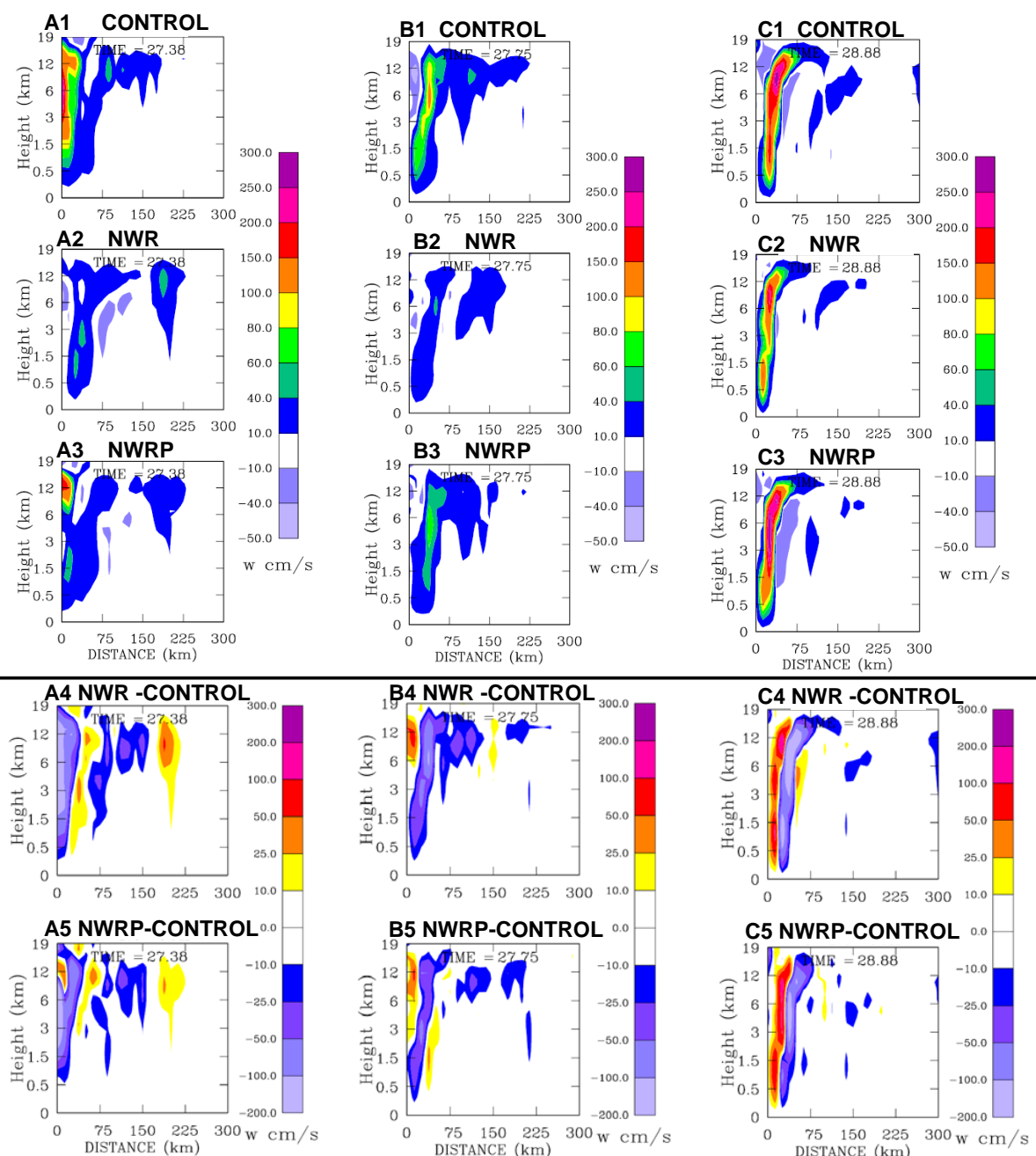

Fig. 4. (d) The same as in Fig. 4a, but for vertical velocity.

100-300 km (Fig. 4a panel B5) and a corresponding decrease in rain water content (Fig. 4c panel B5). The spreading of the zone of enhanced CWC toward the TC center is caused by the radial TC circulation (Fig. 4e).

During the first $12 \mathrm{~h}$, the deep convection at the periphery in NWRP is invigorated (Fig. 4d panel A5), produces more ice at the periphery (Fig. 4b panel A5), precipitates more (Fig. 4c A5) and warms the upper levels (Fig. 4g A5) than in the control. The increase in the updraft at the TC periphery decreases the influx of the air mass to the TC center by more than $5 \mathrm{~m} \mathrm{~s}^{-1}$ (Fig. 4e A5), leading to the weakening of the TC convection at its center, and the weakening of the TC maximum tangential wind by about $5 \mathrm{~m} \mathrm{~s}^{-1}$ (Fig. 4h panel A5) in NWRP relative to that in the control run. Suppressing warm rain everywhere in the NWR run had stronger effects in the same directions (panels A4 at the same figures). The area of strong winds also decreases significantly during the first $24 \mathrm{~h}$ (Fig. 5 panels A and B). The maximum difference in minimum TC pressures in NWRP compared to the Control simulation (WR) of $\sim 10 \mathrm{hPa}$ is reached at about $\mathrm{t}=28: 00$ (i.e. 28 August 2005 00:00 UT), which is $24 \mathrm{~h}$ after the seeding run started (see Fig. 3a).

Note that the suppression of warm rain results in significant changes in the thermodynamic structure of the TC. The main thermodynamic changes are: the decrease in temperature at the low levels at the TC periphery and within the TC eye wall (Fig. 4g panels B5 and C5) for the NWRP run as compared to those in the natural TC (Control run). The decrease at the TC periphery is caused by the enhanced evaporation due to the added amount of cloud water that is less effectively precipitated due to its reduced droplet size. This leads to a corresponding increase in the air humidity (Fig. 4f panels B5 and C5) and decrease in temperature (Fig. 4g panels B5 and C5). A decrease in temperature at the TC center occurred only in the NWR simulation, where warm rain was suppressed also in the eyewall.

After $36 \mathrm{~h}$ the eye of the NWRP run contracted as shown by the radius of peak winds (Fig. 5 panel d; Fig. 6) and the 

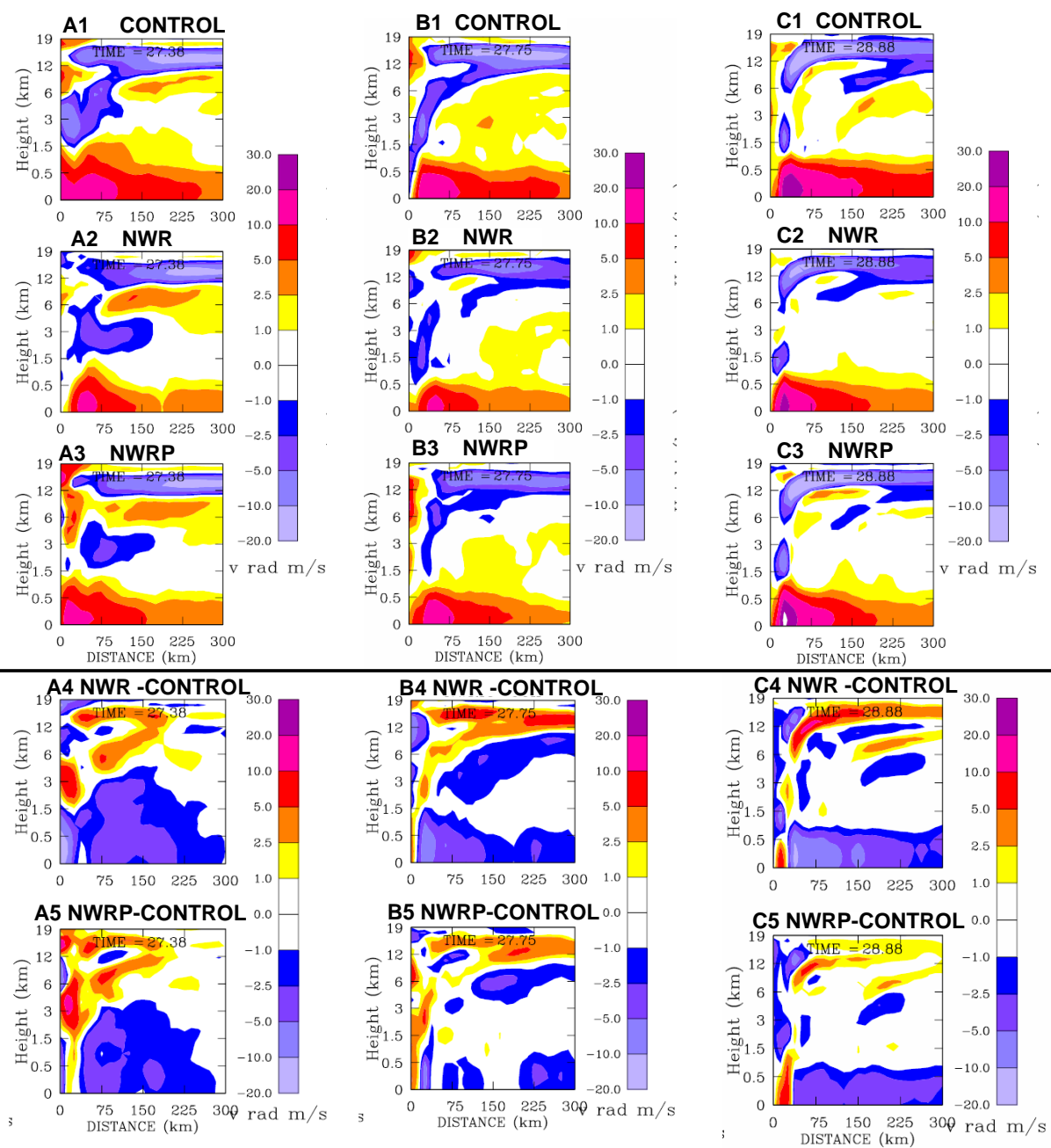

Fig. 4. (e) The same as in Fig. 4a, but for radial velocity field.

central pressure correspondingly decreased (Fig. 3b). At the same time the pressure increased outside of the eye wall. This is manifested as enhanced pressure gradients at the eye wall that leads to intensification of the winds at radial distances less than $30 \mathrm{~km}$ while weakening the winds outside the eye wall, when comparing the NWRP to the Control runs (Fig. $4 \mathrm{~h}$ panel $\mathrm{c} 5$ and Fig. 5 panel d). The relation of the eye diameter to the extent of suppression of warm rain is evident in Figs. 5 and 6, where the peak winds that mark the location of the eyewall occur at progressively smaller radial distances from the TC in the runs with respectively greater suppression of warm rain from the Control to NWRP and NWR simulations. At larger distances from the hurricane center, the wind speed weakens with the progressive suppression of warm rain (see Fig. 7). In fact, the decreasing wind speed from Control to NWRP and NWR at the periphery of the TC is compensated near the center of the TC by the increasing peak wind speeds due to the shrinking of the eye.

\section{Interpretation of the results}

The initial result of suppression of warm rain is warming at the upper levels due to the added release of latent heat of freezing (Pathway E of Fig. 1) and enhancing the updrafts aloft, coupled with low level melting and evaporative cooling (Pathways $\mathrm{C}$ and $\mathrm{H}$ of Fig. 1). As was shown by Khain et al. (2005), this is the typical response of maritime convective clouds to suppression of warm rain due to added large concentrations of small CCN. However, about $12 \mathrm{~h}$ after the initial "seeding" (i.e. suppression of warm rain), the upper level warming became limited to a shallow layer above the freezing level (Fig. 4g) and the enhanced updrafts aloft vanish (Fig. 4d) in the NWRP and NWR runs. Yet, the low level cooling remains at least as strong. The enhanced low level relative humidity (Fig. 4f) implies that this low level cooling occurs due to greater low level evaporation of cloud water that was not precipitated, i.e. moving energy from pathway $\mathrm{D}$ to pathway $\mathrm{C}$ in Fig. 1. This means a net loss of condensation 


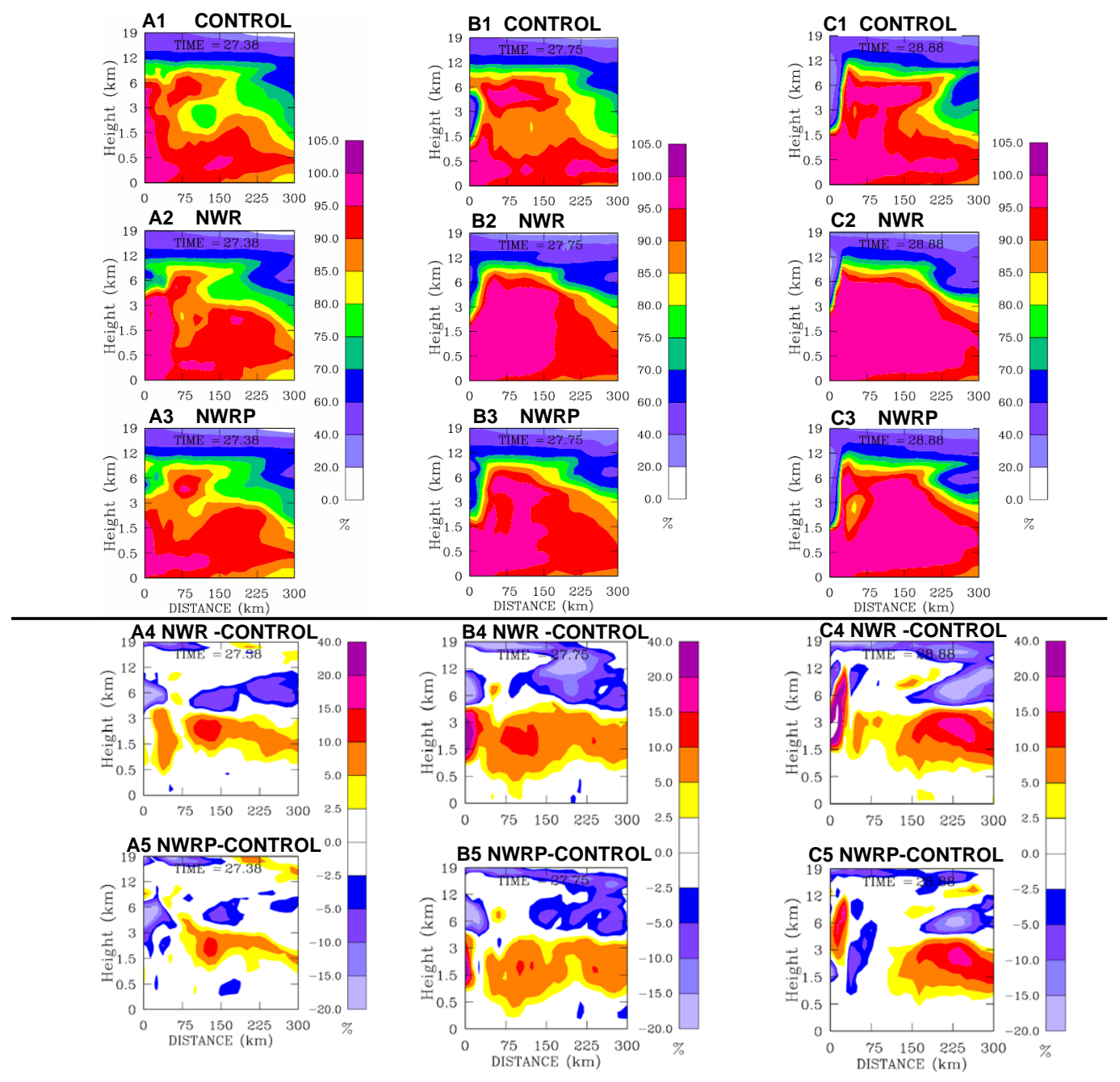

Fig. 4. (f) The same as in Fig. 4a, but for the relative humidity.

latent heating, which leads to less buoyant lower tropospheric air. This is why the evaporative cooling at low levels in the NWR and NWRP cases reduces the deep convective ascent, causing the air to advance closer to the circulation center before eventually being forced to rise. This causes the eye to be more compact. The equivalent potential temperature does not change in the process of evaporation of cloud water. Therefore, when this cooler air is forced to rise it can still form intense deep convection at the eye wall. Based on these considerations, it is suggested here that the continuous cooling at the TC periphery (Fig. 4g panel C5), especially in the TC lowest $3 \mathrm{~km}$, leads to compaction of the TC circulation which can be attributed to the lesser tendency of the more stable low level air to rise before reaching the circulation center. This is supported by the NWR run that has the strongest low level cooling of the three simulations (Fig. $4 \mathrm{~g}$ panels A4, B4 and C4) associated with the greatest extent of suppression of warm rain. The less buoyant low level air supposedly delays rising until it more closely approaches the hurricane center, reducing the radius of the eye even more (see Fig. 6). This idea is also supported by the simulation results of Nong and Emanuel (2003), who showed that low level air with enhanced buoyancy tends to rise before reaching the eyewall and initiate the process of an eyewall replacement with a larger eye (Houze et al., 2007). The buoyancy was enhanced in that simulation by increasing the low level relative humidity without a corresponding decrease in the temperature.

When preventing warm rain also in the center with the NWR run, the intense evaporative cooling takes place within the eye as well (Fig. 4g panels B4, C4), so the temperature gradient is not as strong and the central pressure of the TC is higher as compared to that in other simulations at all times. Consequently, the TC in the NWR run has the largest central pressure, has weakest peak winds and smallest areal extent of hurricane force winds compared to the other simulations (see Figs. 3, 5-7). At 29:00, near the time of the lowest minimum pressure, the radius of the area covered by hurricane force 

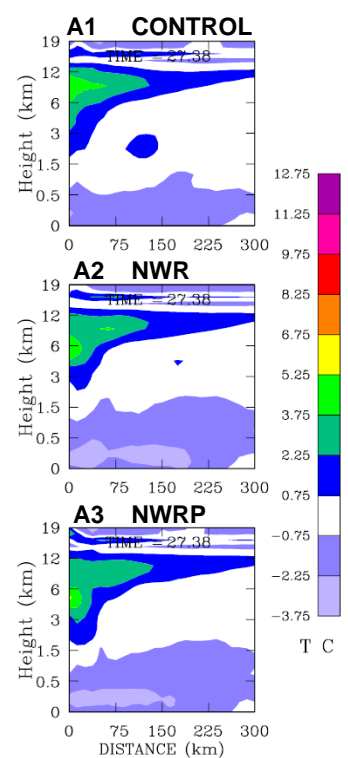

A4 NWR -CONTROL

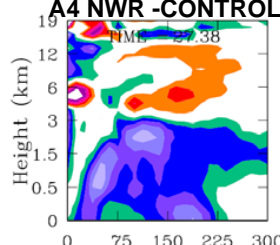

A5 NWRP-CONTROL-

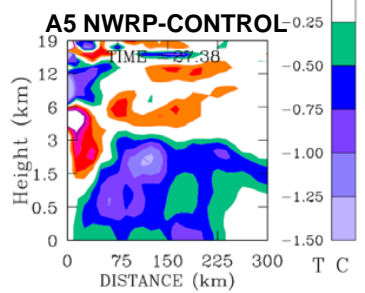

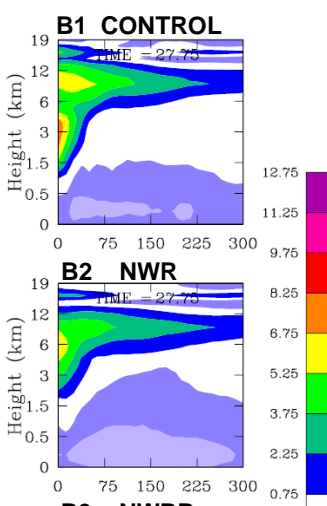

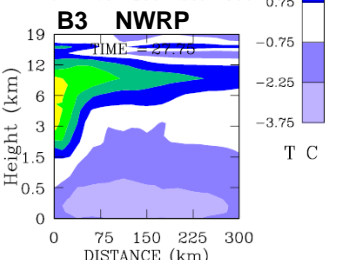

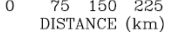
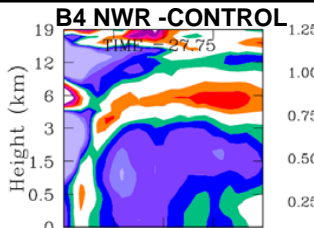

$\begin{array}{lllll}75 & 150 & 225 & 300 & 0.00\end{array}$

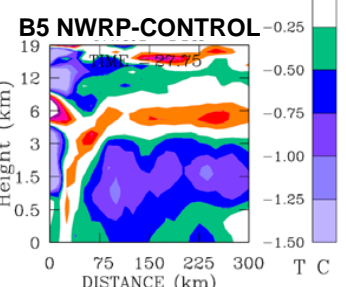

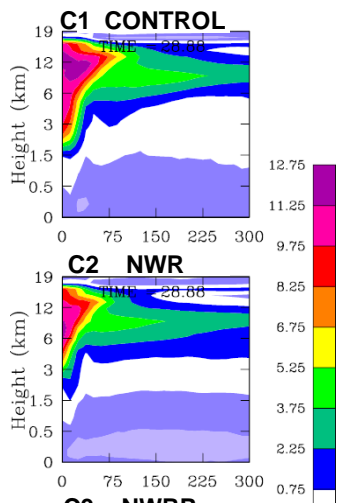
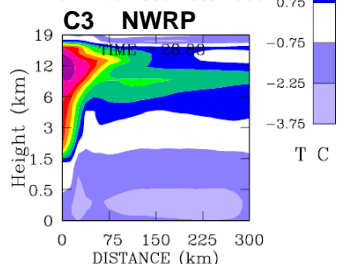

C4 NWR - CONTROL

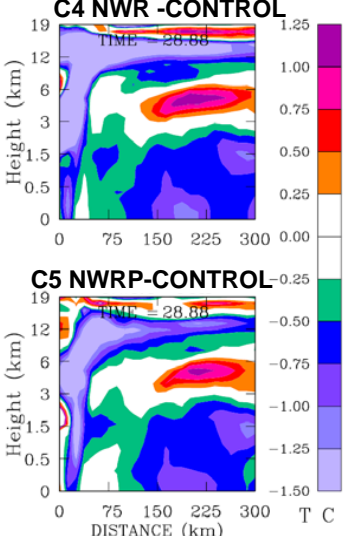

Fig. 4. (g) The same as in Fig. 4a, but for the temperature field.

winds was $108 \mathrm{~km}$ for the control run, $80 \mathrm{~km}$ for the NWRP run and only $62 \mathrm{~km}$ for the NWR run (see Fig. 5f). The radius of maximum winds, which is the radius of the eyewall ring, is not well correlated with the maximum wind intensity, which occurs at the eyewall. There are super hurricanes with large eyes and minimal hurricanes with small eyes. In this particular case (see Fig. 5) the progressive suppression of warm rain from Control to NWRP and NWR reduced the radius covered by hurricane force winds (Fig. 7), but at the same time reduced the radius of the eye (Fig. 6). This contraction of the eye compensated the peak winds in the eyewall for the overall weaker winds in most of the area of the hurricane outward of radial distance of $40 \mathrm{~km}$ from its center. As already suggested here, this relation between the overall TC strength as defined by the radius of hurricane force winds and the compaction of the eye appears to be related to the weakening effect of the low level evaporative cooling. This cooling decreases the tendency of air to ascend until it reaches closer to the circulation center and so shrinks the eye. It should be noted, however, that TCs often undergo periodic changes in the radius of the eye and the respective peak winds for reasons that cannot be related to aerosols (Houze et al., 2007). Fluctuations in the radius of the eye, not necessarily due to an eye replacement cycle, may explain the fluctuations in the observed intensity of Katrina shown in Fig. 2.

The proposed mechanism of low level evaporative cooling due to the suppressed warm rain might explain the strong reduction of the TC intensity in the simulations that did not take sea spray aerosols into account (Cotton et al., 2007), which is similar to the NWR simulation here. It can also explain why adding giant $\mathrm{CCN}$ that enhance warm rain attenuated the weakening effect in that simulation. Unfortunately, insufficient information is provided in their publication for confirming this possibility. 

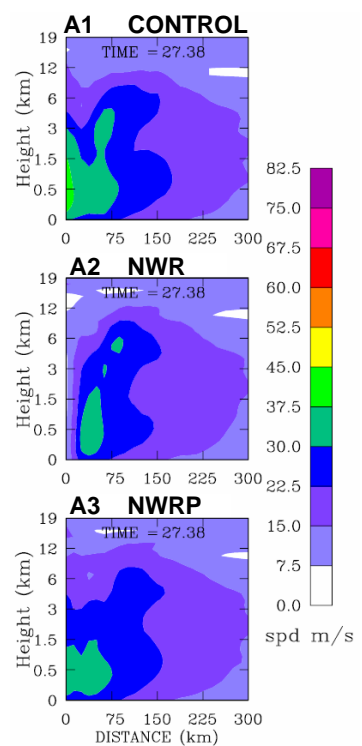

DISTANCE $(\mathrm{km})$
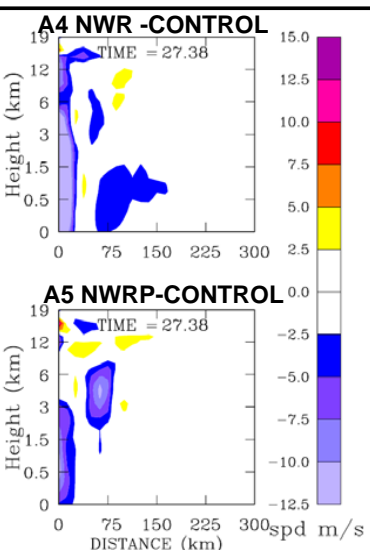

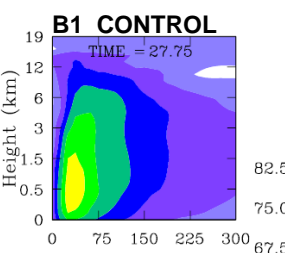

B2 NWR

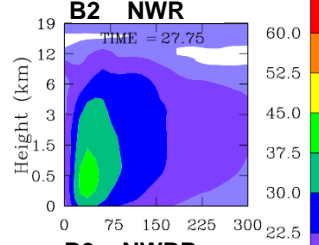

B3 NWRP
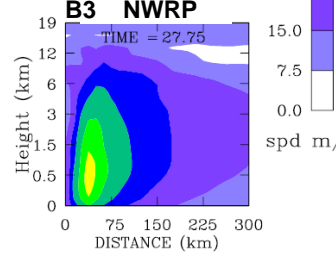

$\operatorname{spd} \mathrm{m} / \mathrm{s}$

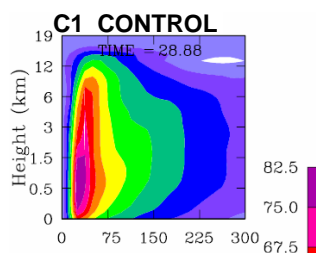

C2 NWR

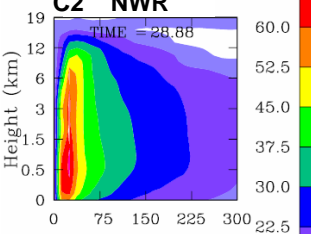

C3 NWRP

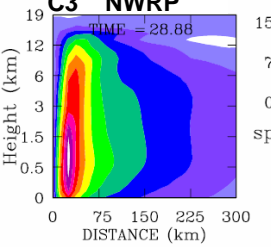

DISTANCE $(\mathrm{km})$
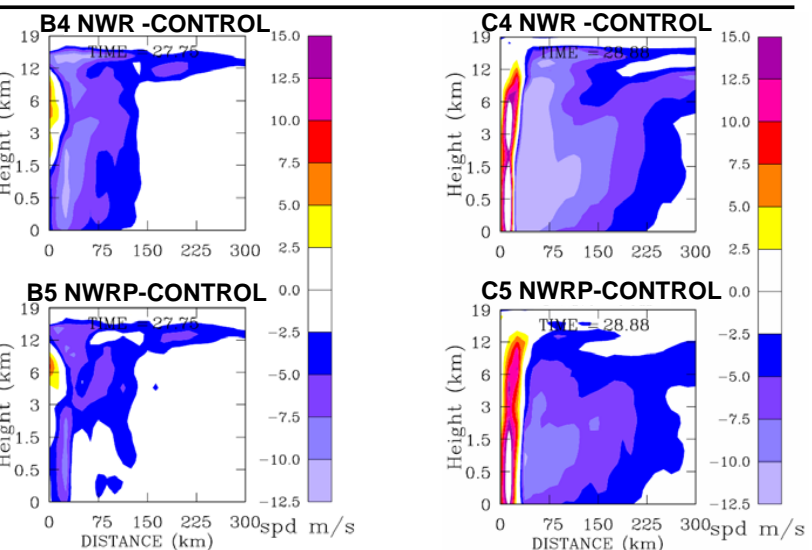

Fig. 4. (h) The same as in Fig. 4a, but for the tangential velocity.

\section{Discussion and conclusions}

The main result of the simulations is that tropical cyclone intensity and structure are apparently sensitive to aerosol concentrations. Physical arguments and numerical simulations indicate that it may be possible to decrease the area covered by hurricane force winds in a TC by injecting small aerosol particles into the air that is ingested into the bases of clouds located on the TC periphery $200-400 \mathrm{~km}$ from its center. In the simulated case the wind speed was decreased by seeding during the whole period of simulations at radial distances $r>40 \mathrm{~km}$ (i.e over the huge area exterior to the eye wall). The low level cooling causes also a contraction of the eye and hence the relative intensification of the eyewall winds, occasionally even matching or exceeding the peak wind intensity of the control simulation. Storm surge is caused by the mean wind over large areas and not by the maximum wind over very small zones. Therefore, even in the cases when peak winds at the eyewall are not reduced, if the seeding leads to a decrease of wind speed over most of the area of hurricaneforce winds and decreasing its areal extent as shown in Fig. 7, it would be an important result.

This provides the basis for seeding experiments, which are practical because wind speeds at distances greater than 200-400 km from TC centers are weak even in very strong hurricanes, which allows operative flights. The following calculations of the relevant orders of magnitudes show that this might be a practical endeavor. Seeding $1 \mathrm{~kg}$ of hygroscopic particles having diameter of $0.1 \mu \mathrm{m}$ and density of $2000 \mathrm{~kg} \mathrm{~m}^{-3}$ can fill homogeneously $1 \mathrm{~km}^{3}$ with a concentration of nearly 1000 particles $\mathrm{cm}^{-3}\left(10^{18}\right.$ particles dispersed in $10^{15} \mathrm{~cm}^{3}$ ). If the seeding is applied around the storm into the converging marine boundary layer that feeds the storm clouds, the seeding rate should be matched to the influx rate. With average inward radial winds of $5 \mathrm{~ms}^{-1}$ at the $0.6 \mathrm{~km}$ deep boundary layer (see Fig. 4a) along the nearly $2000 \mathrm{~km}$ circumference of the radial distance of $300 \mathrm{~km}$ the influx of $60 \mathrm{~km}^{3} \mathrm{~s}^{-1}$. This corresponds to a seeding rate of $60 \mathrm{~kg} \mathrm{~s}^{-1}$, 

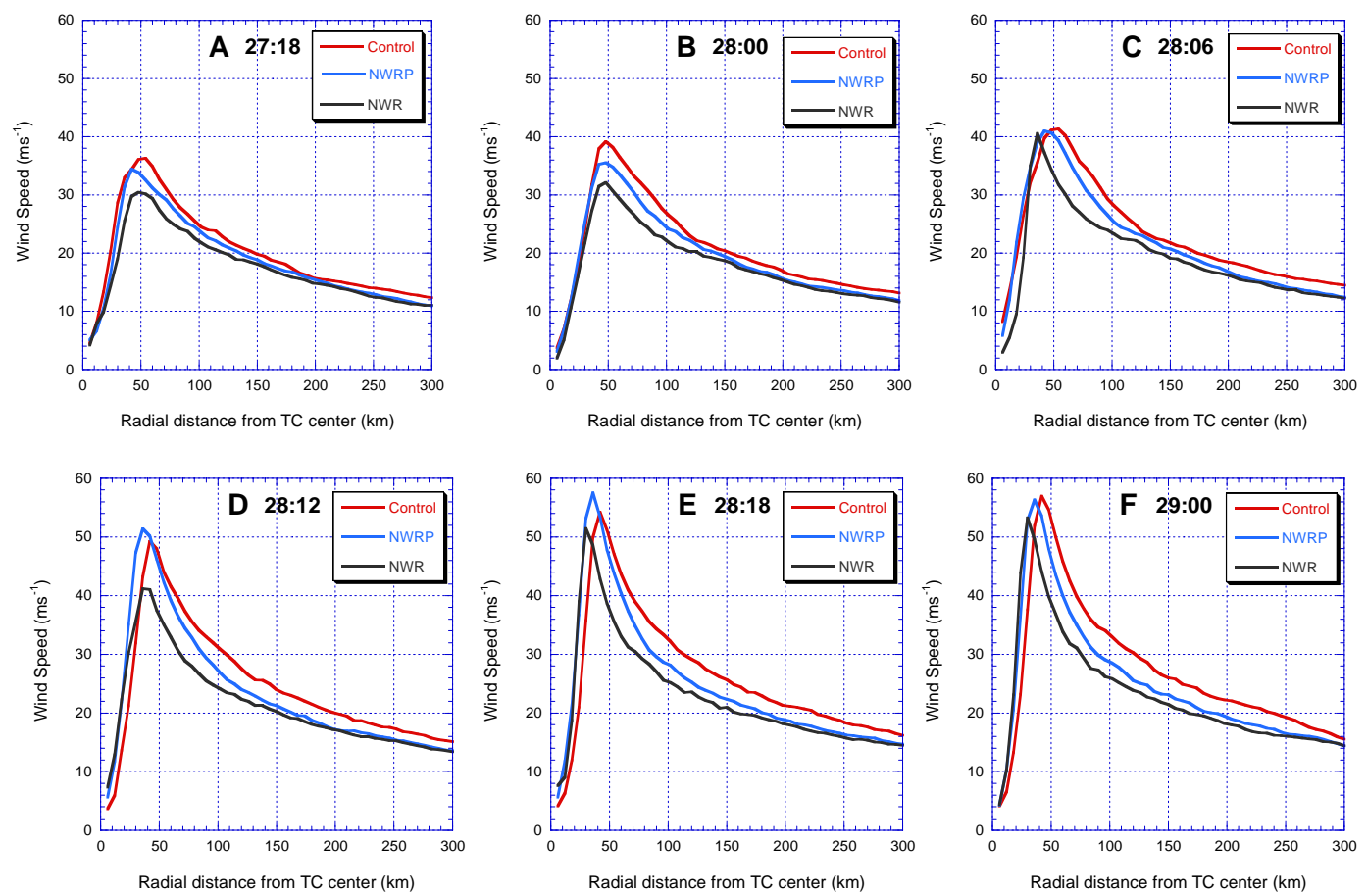

Fig. 5. The simulated radially averaged wind speed of the Control warm rain run, No Warm Rain in the Periphery (NWRP) run, and No Warm Rain (NWR) run, during the evolution of the hurricane. Note the decreasing wind speed from Control to NWRP and NWR and the opposite effect of increasing peak wind speeds due to the decreasing radius of the eye.

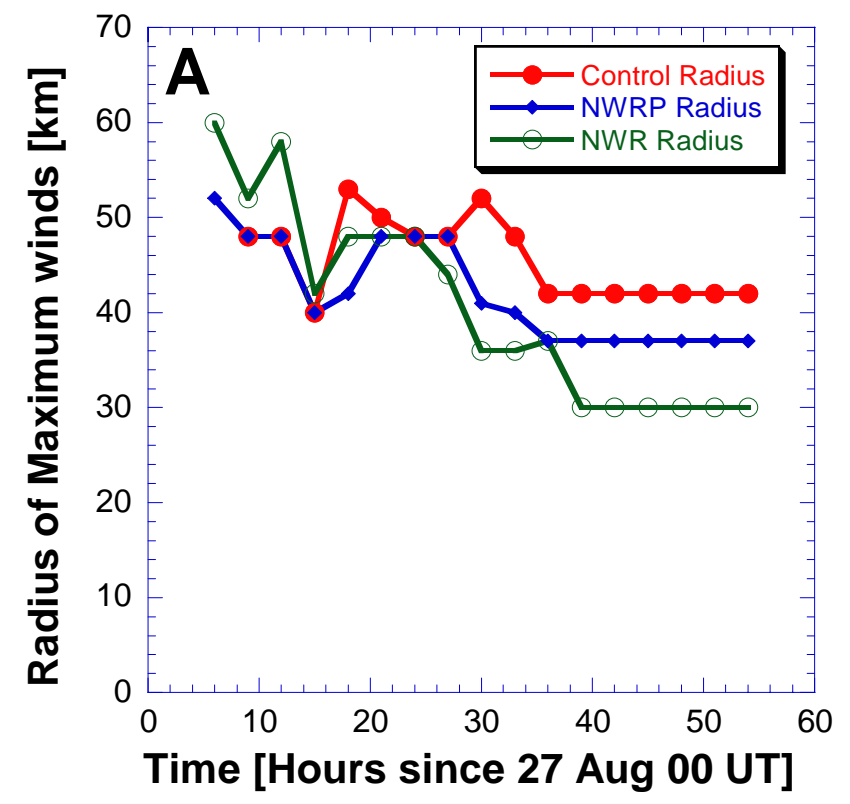

Fig. 6. The radius of the eye for the three simulation experiments. Note the smaller radius of the eye for greater extent of suppression of warm rain, going from the full warm rain control run (WR) to the no warm rain in the periphery (NWRP) and to the fully suppressed warm rain everywhere (NWR).

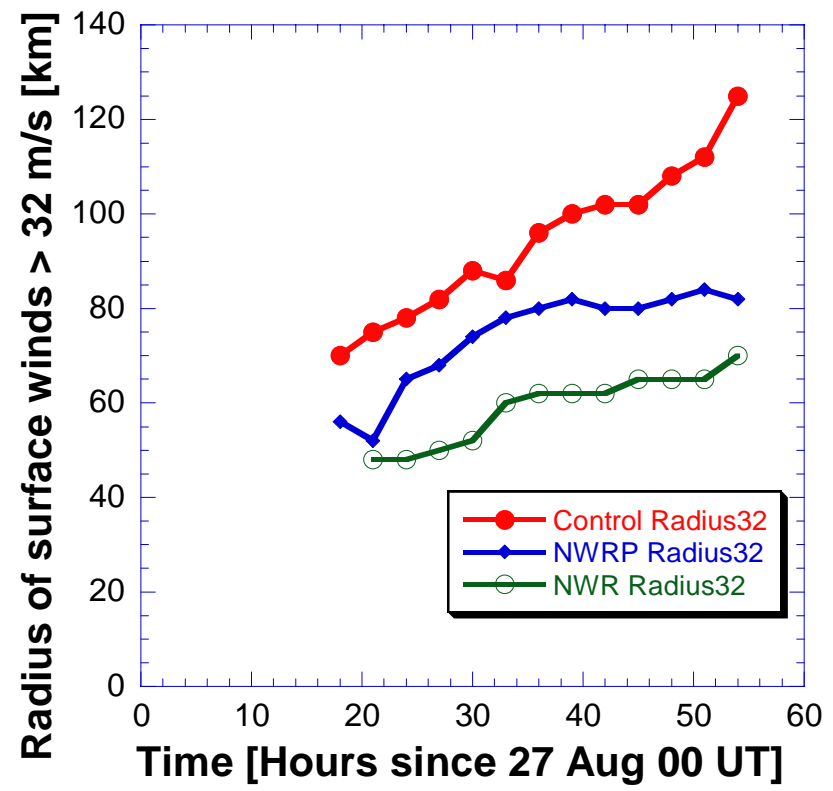

Fig. 7. The radius of the area with hurricane force winds. Note the smaller radius of area with hurricane force winds for greater extent of suppression of warm rain, going from the full warm rain control run (WR) to the no warm rain in the periphery (NWRP) and to the fully suppressed warm rain everywhere (NWR). 
or 216 ton per hour. As far as delivery capacity of the necessary mass of particles is concerned, this seems to be practical with large cargo airplanes having payloads exceeding 100 tons.

This means that seeding the full depth of the marine boundary layer with $0.1 \mu \mathrm{m}$ hygroscopic particles at concentrations of several thousands particles $\mathrm{cm}^{-3}$ is practical at the storm scale. It can be done by dispersing hygroscopic smoke from 5 to 10 cargo airplanes flying in the boundary layer just outside the TC spiral cloud bands so that the particles would be drawn into the storm by the low level convergence after having sufficient time to mix well in the boundary layer.

The apparent susceptibility of the vigor of tropical maritime clouds to small CCN seeding opens the possibility of changing not only the TC intensity, but also its track. Since the tangential velocity (which is orthogonal to the radial velocity) at the radial distances of 50-300 km in the NWRP seeded TC is smaller than that in the control run, the seeded TC moved more eastward due to the beta effect (e.g. Fiorino and Elsberry, 1989; Falkovich et al., 1995) and made landfall $\sim 50 \mathrm{~km}$ farther to the east than the non-seeded TC. Being the weakest, the TC in the NWR run shifted eastwards from the control TC even more (see Fig. 8). In addition, TCs tend to move into the zone of the most developed convection at their periphery (e.g. Falkovich et al., 1995).

These simulations demonstrate that the ability to affect tropical storms is greatest in their organizational and early stages. The seeding window gradually closes with the intensification of the storms, mainly due to the expansion of the wind induced sea spray that enforces warm rain to greater radial distance from the center of the storm. The size of the seeding window in the simulation includes the convective clouds that occurred at radial distances with winds smaller than $22 \mathrm{~ms}^{-1}$. According to the combined information in Figs. 4a and 5 this area included the ring of outer $150 \mathrm{~km}$ of the clouds at $\mathrm{t}=18 \mathrm{~h}$, more than $100 \mathrm{~km}$ into the hurricane at $\mathrm{t}=36 \mathrm{~h}$, and at least $50 \mathrm{~km}$ from the outer edge of the hurricane low clouds at $t=48 \mathrm{~h}$, which was the time of peak intensity.

The simplification of the modeling of the seeding effect has to be taken into account in the interpretation of the results. On the one hand, it is hardly possible to prevent warm rain formation from maritime clouds under simulation of realistic aerosol particle concentrations. However, both remote sensing (Rosenfeld, 1999; Rosenfeld and Woodley, 2003) and in situ (Andreae et al., 2004) observations of tropical clouds interacting with smoke from forest fires demonstrate that warm rain can be shut off entirely in some circumstances. Thus, the simplification indicates the maximum possible effect that could be realized using high aerosol particle concentrations. On the other hand, the utilization of the $3 \mathrm{~km}$ model resolution did not make it possible to resolve the clouds with characteristic scales below about $10 \mathrm{~km}$, which is especially important for clouds at the TC periphery. Besides, the crude resolution significantly decreases the vertical ve-

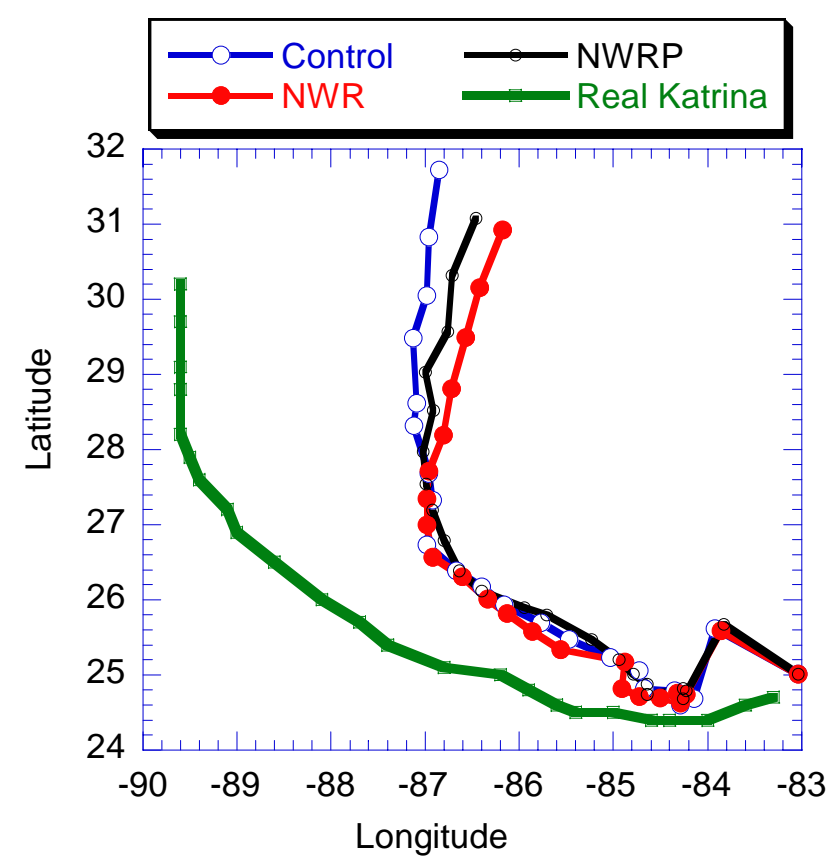

Fig. 8. Time tracks of the observed and simulated hurricane for the Control run with full warm rain, NWR (no warm rain allowed) and NWRP (no warm rain allowed at the periphery). Note that the suppression of warm rain diverts the track eastward.

locities and depths of resolved clouds (Khain et al., 2004). More simulation work with cloud models that address cloud microphysical processes explicitly and the interactions with sea spray aerosols must be done before field experiments can be considered. In any case, the best prospects are in seeding that is aimed at affecting the initial organization and track of the storm. If this study will eventually progress to actual seeding experiments, detecting the seeding effects will be a challenge on the background of natural variability due to changing sea surface temperature and other natural processes. Such experiments will need to be carefully designed along with detailed simulations to yield conclusive results.

Acknowledgements. This study was supported by the European Community-New and Emerging Science and Technologies [Contract No. 12444 (NEST)-ANTISTORM].

Edited by: J. Quaas

\section{References}

Andreae, M. O., Rosenfeld, D., Artaxo, P., Costa, A., Frank, G. P., Longo, K. M., and Silva-Dias, M. A. F.: Smoking rain clouds over the Amazon, Science, 303, 1337-1342, 2004.

Black, R. A. and Hallett, J.: Observations of the distribution of ice in hurricanes, J. Atmos. Sci., 43, 802-822, 1986.

Cotton, W. R., Pielke, R. A. Sr., Walko, R. L., Liston, G. E., Tremback, C. J., Jiang, H., McAnelly, R. L., Harrington, J. Y., 
Nicholls, M. E., Carrio, G. G., and McFadden, J. P.: RAMS 2001: Current status and future directions, Meteor. Atmos. Phys., $82,5-29,2003$

Cotton, W. R., Zhang, H., McFarquhar, G. M., and Saleeby, S. M.: Should we consider polluting hurricanes to reduce their intensity?, J. Weather Modification, in press, 2007.

Falkovich, A. I., Khain, A. P., and Ginis, I. D.: The influence of the air-sea interaction on the development and motion of a tropical cyclone: numerical experiments with a triply nested model, Meteorology and Atmospheric Physics, 55, 167-184, 1995.

Fiorino, M. and Elsberry, R. L.: Some aspects of vortex structure related to the tropical cyclone motion, J. Atmos. Sci. 47, 975990, 1989.

Houze, R. A. Jr., Chen, S. S., Smull, B. F., Lee, W. C., and Bell, M. M.: Hurricane intensity and eyewall replacement, Science, 315, 1235-1239, 2007.

Jorgensen, D. P. and LeMone, M. A.: Vertically Velocity Characteristics of Oceanic Convection, J. Atmos. Scie., 46, 621-640, 1989.

Kain, J. S. and Fritsch J. M.: Convective parameterization for mesoscale models: The Kain-Fritsch scheme, The Representation of Cumulus Convection in Numerical Models, K. A. Emanuel and D. Raymond, Eds., Amer. Meteor. Soc., 246 pp, 1993.

Khain, A. P. and Ginis, I. D.: The mutual response of a moving tropical cyclone and the ocean. Beitr. Phys. Atmosph., 64, 125142, 1991

Khain, A. P., Pokrovsky, A., Pinsky, M., Seifert, A., and Phillips, V.: Effects of atmospheric aerosols on deep convective clouds as seen from simulations using a spectral microphysics mixedphase cumulus cloud model Part 1: Model description, J. Atmos. Sci 61, 2963-2982, 2004.

Khain, A. P., Rosenfeld, D., and Pokrovsky, A.: Aerosol impact on the dynamics and microphysics of convective clouds, Q. J. Roy. Meteor. Soc. 131, 2639-2663, 2005.

Lin, J. C., Matsui, T., Pielke, R. A. Sr., and Kummerow, C.: Effects of biomass-burning-derived aerosols on precipitation and clouds in the Amazon Basin: a satellite-based empirical study, J. Geophys. Res., 111, D19204, doi:10.1029/2005JD006884, 2006.

Lynn, B., Khain, A., Dudhia, J., Rosenfeld, D., Pokrovsky, A., and Seifert, A.: Spectral (bin) microphysics coupled with a mesoscale model (MM5), Part 2: Simulation of a CaPe rain event with squall line, Mon. Wea. Rev., 133, 59-71, 2005.

Michalakes, J., Dudhia, J., Gill, D., Henderson, T., Klemp, J., Skamarock, W., and Wang, W.: The Weather Research and Forecast Model: Software Architecture and Performance, Proceedings of the Eleventh ECMWF Workshop on the Use of High Performance Computing in Meteorology, Eds. Walter Zwieflhofer and George Mozdzynski, World Scientific, 156-168, 2005.

Michalakes, J., Chen, S., Dudhia, J., Hart, L., Klemp, J., Middlecoff, J., and Skamarock, W.: Development of a Next Generation Regional Weather Research and Forecast Model, Developments in Teracomputing: Proceedings of the Ninth ECMWF Workshop on the Use of High Performance Computing in Meteorology, Eds. Walter Zwieflhofer and Norbert Kreitz, World Scientific, 269-276, 2001.

Myhre, G., Storda, F., Johnsrud, M., Kaufman, Y. J., Rosenfeld, D., Storelvmo, T., Kristjansson, J. E., Berntsen, T. K., Myhre, A., and Isaksen, I. S. A.: Aerosol-cloud interaction in- ferred from MODIS satellite data and global aerosol models, Atmos. Chem. Phys., 7, 3081-3101, 2007, http://www.atmoschem-phys.net/7/3081/2007/.

Nong, S. and Emanuel, K.: A numerical study of the genesis of concentric eyewalls in hurricanes, Q. J. R. Met. Soc., 129, 3323 3338, 2003.

Rosenfeld, D.: TRMM Observed First Direct Evidence of Smoke from Forest Fires Inhibiting Rainfall, Geophysical Research Letters, 26(20), 3105-3108, 1999.

Rosenfeld, D.: Suppression of Rain and Snow by Urban and Industrial Air Pollution, Science, 287, 5459, 1793-1796, 2000.

Rosenfeld, D.: Aerosol-Cloud Interactions Control of Earth Radiation and Latent Heat Release, Space Science Reviews, Springer, 9p. 6 December 2006. doi:10.1007/s11214-006-9053-6, http:// dx.doi.org/10.1007/s11214-006-9053-6, 2006.

Rosenfeld, D.: New insights to cloud seeding for enhancing precipitation and for hail suppression, The Journal of Weather Modification, 39, 61-69, 2007.

Rosenfeld, D. and Woodley, W. L.: Closing the 50-year circle: From cloud seeding to space and back to climate change through precipitation physics. Chapter 6 of "Cloud Systems, Hurricanes, and the Tropical Rainfall Measuring Mission (TRMM)" edited by: Tao, W.-K. and Adler, R., 234pp., p. 59-80, Meteorological Monographs 51, AMS, 2003.

Saleeby, S. M. and Cotton, W. R.: A large-droplet mode and prognostic number concentration of cloud droplets in the Colorado State University Regional Atmospheric Modeling System (RAMS), Part I: Module descriptions and supercell test simulations, J. Appl. Meteor., 43, 182-195, 2004.

Segal, Y., Khain, A., Pinsky, M., and Rosenfeld, D.: Effects of hygroscopic seeding on raindrop formation as seen from simulations using a 2000-bin spectral cloud parcel model, Atmos. Res. 71, 3-34, 2004.

Simpson, R. H. and Malkus, J. S.: Experiments in hurricane modification, Sci. Amer., 211, 27-37, 1964

Skamarock, W. C., Klemp, J. B., Dudhia, J., Gill, D. O., Barker, D. M., Wang, W., and Powers, J. G.: A description of the Advanced Research WRF Version 2, NCAR Tech Notes-468+STR, 2005.

Stith, J. L., Dye, J. E., Bansemer, A. A., and Heymsfield, A. J.: Microphysical Observations of Tropical Clouds, J. Appl. Meteor., 41, 97-117, 2002.

Thompson, G., Rasmussen, R. M., and Manning, K.: Explicit Forecasts of Winter Precipitation Using an Improved Bulk Microphysics Scheme, Part I: Description and Sensitivity Analysis, Monthly Weather Rev., 132, 519-542, 2004.

Williams, E., Rosenfeld, D., Madden, M., et al.: Contrasting convective regimes over the Amazon: Implications for cloud electrification, J. Geophys. Res., 107(D20), 8082, doi:10.1029/2001JD000380, 2002.

Willoughby, H. E., Jorgensen, D. P., Black R. A., and Rosenthal, S. L.: Project STORMFURY, A Scientific Chronicle, 1962-1983, Bull. Amer. Meteor. Soc., 66, 505-514, 1985.

Woodcock, A. H.: Salt nuclei in marine air as a function of altitude and wind force, J. Meteor., 10, 362-371, 1953.

Van den Heever, S. C., Carrió, G. G., Cotton, W. R., Demott, P. J., and Prenni, A. J.: Impacts of Nucleating Aerosol on Florida Storms. Part I: Mesoscale Simulations, J. Atmos. Sci., 63, 17521775, 2006. 